\title{
DA EFETIVIDADE DO TEXTO LEGISLATIVO NA PROTEÇÃO DA COMUNIDADE LGBTQIA+
}

\author{
Maria Oderlândia Duarte Cremer ${ }^{1}$ \\ Emerson Oliveira de Faria ${ }^{2}$
}

\begin{abstract}
RESUMO: O presente artigo busca realizar uma análise qualitativa das disposições encontradas nas fontes do direito para averiguar se a presença ou ausência da definição dos grupos que compõem a comunidade LGBTQIA+ e de noções de identidade de gênero e orientação sexual são relevantes para a devida efetividade dos dispositivos legislativos aplicados ao caso concreto, buscando com mais enfoque na ação direta de inconstitucionalidade por omissão de número 26 e nas leis ordinárias e complementares. Também busca analisar o contexto fático e histórico-social nos quais a efetivação dos dispositivos legais é feita, para certificar-se se a efetividade dos dispositivos é afetada pelos servidores do Estado ou não.
\end{abstract}

Palavras- chave: Homofobia. Legislação Brasileira. LGBT. Transfobia.

ABSTRACT: The following article seeks to make a qualitative analysis of the dispositions found in the Brazilian law sources to check if the presence or absence of a definition of the groups that make up the LGBTQIA+ community and other gender identity and sexual orientation concepts are relevant for the effectiveness of the dispositions used in legal cases, searching with focus in the direct action of unconstitutionality by omission number 26 and in Brazilian ordinary and complementary laws. This article also seeks to analyze the factual and historical-social context in which the laws are applied to, to certify if the effects of the law are affected by state servers and employees.

Keywords: Brazilian Law. Homophobia. LGBT. Transphobia.

\section{INTRODUÇÃO}

O Brasil é, em seu texto constitucional, um país de todos, onde seu povo é protegido da discriminação e do preconceito, não devendo ser distinguido por raça, cor, gênero ou quaisquer outras formas de discriminação ${ }^{3}$, porém isso não ocorre na prática. São perceptíveis a discriminação e o preconceito que a comunidade LGBTQIA+ sofre

\footnotetext{
${ }^{1}$ Acadêmica do curso de Direito pela Faculdade Interamericana de Porto Velho- UNIRON. E-mail: oderlandia.duarte@hotmail.com.

${ }^{2}$ Prof. Orientador pela Faculdade Interamericana de Porto Velho- UNIRON. Doutor em Direito Constitucional, Mestre em Direito Empresarial e Especialista em Direito Civil. E-mail: emerson.faria@uniron.edu.br.

${ }^{3}$ BRASIL. [Constituição (1988)]. Constituição da República Federativa do Brasil de 1988. Brasília, DF: Presidência da República, [2016]. Disponível em: http://www.planalto.gov.br/ccivil_03/constituicao/constituicao.htm. Acesso em: 13 abr. 2021.
} 
frequentemente, e mesmo assim a lei brasileira não possui dispositivos que imponham a devida proteção à essa parcela da população que se encontra em posição de vulnerabilidade.

O que é chamado de comunidade LGBT, LGBTQ, LGBTQIA+ ou outras siglas, compreende a junção de várias comunidades, sendo as letras que compõem a sigla LGBTQIA+ referentes à: Lésbicas, Gays, Bissexuais, Transexuais, Queers, Intersexuais, Agêneros e Assexuados e outros. ${ }^{4}$

É importante notar inicialmente que a legislação brasileira não abarca os conceitos de identidade de gênero, sexo biológico e orientação sexual, sendo estes essenciais ao melhor entendimento do assunto.

O sexo biológico ${ }^{5}$, a identidade de gênero ${ }^{6}$ e a orientação sexual7 são independentes entre si.

O sexo biológico diz respeito ao corpo físico de um indivíduo, que pode ter características do sexo masculino, como mais massa muscular, maior presença de pelos, presença de pênis e testículos e voz grave; do sexo feminino, como menor presença de pelos, maior presença de gordura nas nádegas, presença de seios desenvolvidos e vagina; ou de ambos os sexos, sendo neste caso chamado de intersexo. ${ }^{8}$

A identidade de gênero diz respeito a autoconsciência de um indivíduo em relação ao seu próprio gênero, que pode identificar-se como mulher, homem ou não-binário, e pode alterar-se ou não. A identidade de gênero é, geralmente, consolidada por volta dos três anos, e alguns estudiosos dizem ser uma construção social enquanto outros afirmam haver uma predisposição genética. Pessoas cuja identidade de gênero é oposta à de seu sexo biológico são chamadas de pessoas trans, pessoas cuja identidade de gênero seja igual de seu sexo biológico são chamadas de pessoas cis e pessoas cuja identidade de gênero e sexo biológico não sejam opostos ou alinhados são chamadas de não-binárias. ${ }^{9}$

${ }^{4}$ BORTOLETTO, Guilherme Engelman. LGBTQIA+: identidade e alteridade na comunidade. Trabalho de conclusão de curso apresentado como requisito parcial para obtenção do título de Especialista em Gestão de Produção Cultural. São Paulo/SP, 2019. p. 5.

${ }^{5}$ BERRILL, N. J.. Sex. Encyclopædia Britannica Online. 2013. Disponível em: https://www.britannica.com/science/sex. Acesso em: 13 abr. 2021

${ }^{6}$ BRITANNICA, The Editors of Encyclopædia. Gender identity. Encyclopædia Britannica Online. 202o. Disponível em: https://www.britannica.com/topic/gender-identity. Acesso em: I3 Abr. 202I.

${ }^{7}$ Answers to your questions for a better understanding of sexual orientation and homosexuality. American Psychological Association. 2008. Disponível em: https://www.apa.org/topics/lgbtq/orientation. Acesso em: 13 Abr. 202I

${ }^{8}$ WHAT is intersex?. Intersex Human Rights Australia. 2013. Disponível em: https://ihra.org.au/18106/what-is-intersex/. Acesso em: 13 abr. 2021

${ }^{9}$ BERRILL, N. J.. Sex. Encyclopædia Britannica Online. 2013. Disponível em: https://www.britannica.com/science/sex.

Acesso em: 13 abr. 2021 
Queer (em português 'excêntrico', 'insólito') é uma palavra proveniente do inglês usada para designar pessoas fora das normas de gênero, seja pela sua orientação sexual, identidade ou expressão de gênero, ou características sexuais. ${ }^{10}$

A orientação sexual diz respeito a atração sexual e romântica do indivíduo por pessoas de um ou mais sexos ou gêneros em relação ao seu próprio gênero. A orientação sexual é um espectro, e não é solidamente definida, porém há convenções a respeito das orientações sexuais, sendo as definições mais comuns: Heterossexualidade, quando há atração pelo gênero ou sexo oposto; Homossexualidade, quando há atração pelo mesmo gênero ou sexo; Bissexualidade, quando há atração por mais de um gênero ou sexo em iguais ou diferentes medidas; e Assexualidade, quando não há atração por qualquer gênero ou sexo.

Apesar da imensa variedade de combinações de orientação sexual, identidade de gênero e sexo biológico, a comunidade LGBTQIA+ sofre com preconceito e discriminação recorrentes, oriundos da intolerância e da incompreensão. ${ }^{\text {II }}$

Figura I - Mandala da Diversidade Sexual

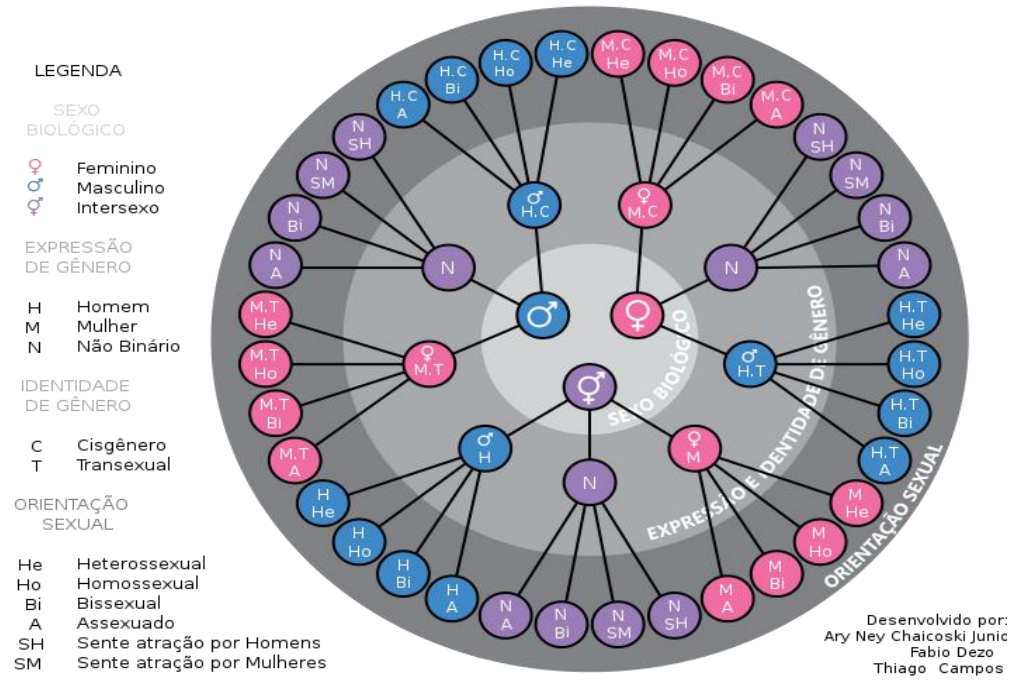

Fonte: Wikimedia Commons, 2019. ${ }^{12}$

ro BORTOLETTO, Guilherme Engelman. LGBTQIA+: identidade e alteridade na comunidade. Trabalho de conclusão de curso apresentado como requisito parcial para obtenção do título de Especialista em Gestão de Produção Cultural. São Paulo/SP, 2019.

"Id. Ibid., p. 5 .

${ }^{12}$ MANDALA da Diversidade Sexual. Ary Ney Chaicoski Junior, Fabio Dezo, Thiago Campos. 2019. CC BY-SA 4.o. https://creativecommons.org/licenses/by-sa/4.o, via Wikimedia Commons. Disponível em: https://commons.wikimedia.org/wiki/File:Mandala_da_Diversidade_Sexual.svg. Acesso em: I3 abr. 202I. 
Porém, mesmo com a evidente luta da comunidade LGBTQIA+, a legislação brasileira apenas recentemente criminalizou a homotransfobia ${ }^{13}$, equiparando-a aos crimes de racismo, fazendo-o por meio da Ação Direta de Inconstitucionalidade por Omissão 26 Distrito Federal (ADO no 26/DF). ${ }^{14}$ Mas não há lei específica do âmbito penal que ampare e projeta a comunidade LGBTQIA+, sendo nebulosa a efetividade da ADO nº 26/DF.

\section{DESENVOLVIMENTO}

Face o exposto, o presente artigo tem como objetivo verificar a efetividade da legislação brasileira quanto à proteção da comunidade LGBTQ+ quando aplicada ao caso concreto.

Para isso, verificando o quão efetiva é o texto da legislação brasileira em relação a prevenção, repressão e reparação da homotransfobia por meio da análise do texto do ordenamento jurídico, averiguando se a legislação brasileira versa de maneira taxativa sobre os conceitos relativos a identidade de gênero e orientação sexual e se a presença ou ausência destas disposições são de relevância para a devida eficácia neste âmbito. Desta forma, este artigo, sendo uma pesquisa exploratória explicativa, realizará a análise dos elementos supramencionados e, se necessário, de sua aplicação no caso concreto, para elucidar os questionamentos levantados.

\section{I Da Terminologia e Disposições das Fontes do Direito}

Para determinar corretamente a efetividade é necessário primeiro que seja realizada uma busca nas fontes do direito por termos e designações atribuídas a comunidade LGBTQ+ e as subcomunidades componentes, se estes são abarcados pelo ordenamento jurídico e similares.

\section{I.I Das Disposições Encontradas em Lei Ordinária e Lei Complementar}

Após procura realizada no site oficial do Planalto (www.planalto.gov.br), foi encontrado uma disposição que menciona o termo 'orientação sexual', no art. Io da Lei I0.216 de 200I, conhecida como Lei Antimanicomial ou Lei Paulo Delgado, com a seguinte redação:

\footnotetext{
${ }^{13}$ STF enquadra homofobia e transfobia como crimes de racismo ao reconhecer omissão legislativa. Brasília, I3 jun. 2019. Disponível em: http://portal.stf.jus.br/noticias/verNoticiaDetalhe.asp?idConteudo=414010. Acesso em: 13 abr. 2021. ${ }^{14}$ BRASIL. Supremo Tribunal Federal. Ação direta de inconstitucionalidade por omissão no 26/DF - Distrito Federal. Relator: Ministro Celso de Mello. 2019. Disponível em: http://www.stf.jus.br/arquivo/cms/noticiaNoticiaStf/anexo/ADO26votoMAM.pdf. Acesso em: 13 abr. 202I.
} 
Art. Io Os direitos e a proteção das pessoas acometidas de transtorno mental, de que trata esta Lei, são assegurados sem qualquer forma de discriminação quanto à raça, cor, sexo, orientação sexual, religião, opção política, nacionalidade, idade, família, recursos econômicos e ao grau de gravidade ou tempo de evolução de seu transtorno, ou qualquer outra. ${ }^{\text {is }}$

Esta é uma das menções mais antigas encontradas em texto de lei ordinária brasileira, a Lei Paulo Delgado é oriunda do movimento antimanicomial que ocorreu por volta do final do século XX e é considerada um grande marco na história do movimento. ${ }^{16}$

Há também outro dispositivo que menciona o mesmo termo, o art. $5^{\circ}$, sún. da Lei Maria da Penha, Lei II.340 de 2006:

Art. $5^{\circ}$ Para os efeitos desta Lei, configura violência doméstica e familiar contra a mulher qualquer ação ou omissão baseada no gênero que lhe cause morte, lesão, sofrimento físico, sexual ou psicológico e dano moral ou patrimonial:

I - no âmbito da unidade doméstica, compreendida como o espaço de convívio permanente de pessoas, com ou sem vínculo familiar, inclusive as esporadicamente agregadas;

II - no âmbito da família, compreendida como a comunidade formada por indivíduos que são ou se consideram aparentados, unidos por laços naturais, por afinidade ou por vontade expressa;

III - em qualquer relação íntima de afeto, na qual o agressor conviva ou tenha convivido com a ofendida, independentemente de coabitação.

Parágrafo único. As relações pessoais enunciadas neste artigo independem de orientação sexual. ${ }^{17}$

É importante notar que a entendimento de "mulher" na Lei Maria da Penha não realiza distinção se esta é de gênero feminino ou sexo feminino, o que, por interpretação extensiva, depreende que a lei protege também as mulheres transexuais, que podem ser vítimas de violência em decorrência de seu gênero. Esta interpretação da Lei Ir.340/o6 conta com jurisprudências favoráveis, como a decisão do processo no oor8790-25.2017.8.19.0004 a seguir:

A requerente se veste como mulher, se identifica socialmente como mulher, ingere medicamentos hormonais femininos, ou seja, se vê e se compreende como mulher, não possuindo terceira pessoa autoridade para a designar de outra forma.

$[\ldots]$

\footnotetext{
${ }^{15}$ BRASIL. Lei no ${ }^{\circ}$ I0.216 de 6 de abril de 200I. Dispõe sobre a proteção e os direitos das pessoas portadoras de transtornos mentais e redireciona o modelo assistencial em saúde mental. Diário Oficial da União: seção I, Brasília, DF, p. 2, o9 abr. 200I. Disponível em: http://www.planalto.gov.br/ccivil_03/leis/leis_200I/lio216.htm. Acesso em: 09 set 202I.

${ }^{16}$ FILHO, Kleber Prado e LEMOS, Flavia Cristina Silveira. Uma breve cartografia da luta antimanicomial no Brasil. Contemporânea - Revista de Sociologia da UFSCar. São Carlos, v. 2, n. I, jan-jun 2012, pp. 45-63. Disponível em: https://www.contemporanea.ufscar.br/index.php/contemporanea/article/view/59/32. Acesso em: o9 set 2021 ${ }^{17}$ BRASIL. Lei no ${ }^{1} 1.340$ de 07 de agosto de 2006. Cria mecanismos para coibir a violência doméstica e familiar contra a mulher [...] e dá outras providências. Diário Oficial da União: seção I, Brasília, DF, p. I, o8 ago. 20o8. Disponível em: http://www.planalto.gov.br/ccivil_03/_ato2004-2006/2006/lei/lir340.htm. Acesso em: 09 set. 202I.
} 
Com efeito, não há dúvida de que a questão dos autos envolve uma discussão e opressão sobre o gênero feminino, o que encontra abrigo no art. $5^{\circ}$ da Lei Maria da Penha. ${ }^{18}$

A decisão em voga afasta a interpretação de que a "mulher" a qual se refere a Lei Maria da Penha diz respeito ao sexo, e não ao gênero, sendo lógico o entendimento que esta Lei proteja também as mulheres trans.

Porém, alguns juristas não entendem desta forma e perpetuam a transfobia nos tribunais, tratando mulheres transgênero na flexão masculina da língua portuguesa e recusando-se a aplicar a Lei Maria da Penha no caso concreto. ${ }^{19}$

Não há consenso entre os Tribunais de Justiça de cada unidade federativa, que interpretam o texto da Lei Maria da Penha tanto de maneira a proteger as mulheres transexuais quanto de maneira a negar a proteção a estas. Porém, já existem medidas protetivas em favor de mulher trans a serem julgadas pelo STJ, o que pode gerar forte precedente favorável as transexuais na interpretação da lei. ${ }^{20}$

Desta forma, não podemos falar que o texto da legislação é insuficiente ou ineficiente na proteção daqueles que busca proteger, já que é capaz de efeitos plenamente, sem debilidade decorrente de sua redação, mas sim que os operadores do direito falham ao não admitir uma interpretação do texto legislativo que permita a proteção de todas as mulheres. Isso sugere a presença da LGBTfobia entre os operadores do direito e no âmbito judiciário.

\subsubsection{Da Ação Direta de Inconstitucionalidade por Omissão n. 26}

A Ação Direta de Inconstitucionalidade por Omissão 26 ( $\mathrm{ADO}$ 26/DF) é o marco que definiu a conduta homotransfóbica como equivalente a conduta racista, portanto equiparando crimes LGBTfóbicos aos crimes de racismo.

No inteiro teor da ADO 26/DF, o termo "LGBT" e suas variações são conceituadas pelo relator Ministro Celso de Mello da seguinte forma:

[...] aos integrantes da comunidade LGBTTT (Lésbicas, Gays, Bissexuais, Travestis, Transsexuais e Transgêneros), doravante referida apenas como LGBT

\footnotetext{
${ }^{18}$ RIO DE JANEIRO. Tribunal de Justiça do estado do Rio de Janeiro, Comarca de São Gonçalo. Decisão. Processo no oor8790-25.2017.8.19.0oo4. Juízo de Direito da Vara de Violência Doméstica e Familiar Contra a Mulher. Disponível em: https://www.conjur.com.br/dl/lei-maria-penha-tambem-protege-mulher.pdf. Acesso em: o9 set 2021.

${ }_{19}$ LAVIERI, Fernando. As trans exigem a lei Maria da Penha. ISTOÉ. Rio de Janeiro, n. 2696. 17 set. 2021. Comportamento. Disponível em: https://istoe.com.br/as-trans-exigem-a-lei-maria-da-penha/. Acesso em: 25 set 202I.

20 STJ julgará medidas protetivas em favor de mulher trans. Migalhas, [S. 1.], 30 maio 202i. Disponível em: https://www.migalhas.com.br/quentes/346238/stj-julgara-medidas-protetivas-em-favor-de-mulher-trans. Acesso em: 27 out. 2021.
} 
(tal como o faz o autor da presente demanda), sigla também conhecida, mais recentemente, como LGBTT+ (Lésbicas, Gays, Bissexuais, Travestis, Transsexuais e Intersexos), abrangidas pelo sinal aditivo + todas as outras identidades $[\ldots]^{21}$

O relator, em seu voto, deixa claro e explícito que a sigla LGBT+ abrange não só lésbicas, gays, bissexuais, transexuais e transgêneros, mas sim todas as identidades que se encontram em posição de vulnerabilidade em decorrência de sua orientação sexual ou identidade de gênero.

Também na Ação Direta de Inconstitucionalidade por Omissão 26, a Douta Procuradoria Geral da República formula em parecer a composição da sigla LGBT da seguinte forma:

[...] Deve conferir-se interpretação conforme a Constituição ao conceito de raça previsto na Lei 7.716 , de 5 de janeiro de 1989 , a fim de que se reconheçam como crimes tipificados nessa lei comportamentos discriminatórios e preconceituosos contra a população LGBT (lésbicas, gays, bissexuais, travestis, transexuais e transgêneros). Não se trata de analogia 'in malam partem' ${ }^{22}$

O relator Ministro Celso de Mello também afirma na $\mathrm{ADO} 26$ / DF que a sigla LGBT refere-se à orientação sexual e identidade de gênero ao citar a incriminação de atos em razão de orientação sexual ou identidade de gênero:

[...] obrigação de editar o diploma legislativo necessário à incriminação dos atos e comportamentos resultantes de discriminação ou de preconceito contra pessoas em razão de sua orientação sexual ou em decorrência de sua identidade de gênero. ${ }^{23}$

Esta afirmação confirma o entendimento de que a comunidade LGBT como um todo encontra-se em posição de vulnerabilidade, e que há uma omissão legislativa quanto a este tópico.

O voto do relator Ministro Celso de Mello também trabalha as questões terminológicas e pincela as problemáticas envolvidas na caracterização da comunidade LGBTQIA+ em seu voto, como dispõe:

Presente o contexto ora delineado, entendo relevante fazer algumas observações prévias que reputo essenciais à formulação do meu voto.

É preciso esclarecer, desde logo, que a sigla LGBT, no contexto dos debates nacionais e internacionais sobre a questão da diversidade sexual e de gênero, tem

\footnotetext{
${ }^{21}$ BRASIL. Supremo Tribunal Federal. Inteiro Teor da Ação Direta de Inconstitucionalidade por Omissão n. 26. Relator Celso de Mello. Diário de Justiça n. oI/o7/2019, p. is. Disponível em: http://portal.stf.jus.br/processos/detalhe.asp?incidente $=4515053$. Acesso em: 26 ago. 2021.

${ }^{22}$ Id. Ibid. p. 17

${ }^{23}$ BRASIL. Supremo Tribunal Federal. Inteiro Teor da Ação Direta de Inconstitucionalidade por Omissão n. 26. Relator Celso de Mello. Diário de Justiça n. or/o7/2019, p. 38. Disponível em: http://portal.stf.jus.br/processos/detalhe.asp?incidente=4515053. Acesso em: 26 ago. 202I.
} 
sido utilizada para designar a comunidade global das pessoas lésbicas, gays, bissexuais, travestis, transgêneros, intersexuais, além de outras definidas por sua orientação sexual ou identidade de gênero. ${ }^{24}$

O discurso explicita que a comunidade LGBTQIA+ é formada não só pelos termos que compõem seu acrônimo como também por todos aqueles de orientação sexual ou identidade de gênero não heteronormativas, como complementa o próprio relator:

A expressão LGBT, além de possuir a virtude de haver sido formulada pela própria comunidade que designa, atingiu ampla aceitação pública e consenso internacional, consagrando-se sua utilização, no Brasil, em 08/o6/20o8, na I Conferência Nacional de Gays, Lésbicas, Bissexuais, Travestis e Transexuais (convocada por meio do decreto presidencial de 28 de novembro de 2007), cabendo assinalar, no entanto, que a primazia conferida ao uso desse termo decorre, exclusivamente, do prestígio e do renome que o acrônimo LGBT adquiriu no âmbito da defesa dos direitos humanos e do combate à discriminação, sem que o seu emprego signifique indiferença ou esquecimento em relação às demais siglas também utilizadas, especialmente com o propósito de fazer incluir, em sua definição, as pessoas que se identificam como "queer" (LGBTQ), as pessoas intersexuais (LGBTQI), as pessoas assexuais (LGBTQIA) e todas as demais pessoas representadas por sua orientação sexual ou identidade de gênero (LGBTQI+).25

Continua o relator, trazendo uma definição do que pode ser compreendido por “comunidade LGBT":

É possível constatar, a partir dessa breve exposição, que a comunidade LGBT, longe de constituir uma coletividade homogênea, caracteriza-se, na verdade, pela diversidade de seus integrantes, sendo formada pela reunião de pessoas e grupos sociais distintos, apresentando elevado grau de diferenciação entre si, embora unidos por um ponto comum: a sua absoluta vulnerabilidade agravada por práticas discriminatórias e atentatórias aos seus direitos e liberdades fundamentais. ${ }^{26}$

O ponto trazido pelo relator neste fragmento textual é de extrema relevância, pois serve como indicador de que a posição de vulnerabilidade da comunidade LGBT é decerto um dos fatores significadores da comunidade LGBT, que sofre constantemente com, nas palavras do relator, "práticas discriminatórias e atentatórias aos seus direitos e liberdades" ${ }^{27}$ E, como última menção para os propósitos deste estudo, o relator Ministro Celso de Mello traz pontos que fundamentam a vulnerabilidade da comunidade LGBT:

É preciso enfatizar, neste ponto, que o gênero e a orientação sexual constituem elementos essenciais e estruturantes da própria identidade da pessoa humana, integrando uma das mais íntimas e profundas dimensões de sua personalidade, consoante expressiva advertência de autorizado magistério doutrinário [...]

\footnotetext{
${ }^{24}$ Id. Ibid. p. 42

${ }^{25}$ Id. Ibid. p. 42.

${ }^{26}$ BRASIL. Supremo Tribunal Federal. Inteiro Teor da Ação Direta de Inconstitucionalidade por Omissão n. 26. Relator Celso de Mello. Diário de Justiça n. or/o7/2019, p. 43. Disponível em: http://portal.stf.jus.br/processos/detalhe.asp?incidente $=4515053$. Acesso em: 26 ago. 2021 .

${ }^{27}$ Id. Ibid. p. 43
} 
Não obstante as questões de gênero envolvam, inegavelmente, aspectos fundamentais relacionados à liberdade existencial e à dignidade humana, ainda assim integrantes da comunidade LGBT acham-se expostos, por ausência de adequada proteção estatal, especialmente em razão da controvérsia gerada pela denominada "ideologia de gênero", a ações de caráter segregacionista, impregnadas de inequívoca coloração homofóbica, que visam a limitar, quando não a suprimir, prerrogativas essenciais de gays, lésbicas, bissexuais, travestis, transgêneros e intersexuais, entre outros, culminando, até mesmo, em algumas situações, por tratá-los, absurdamente, a despeito de sua inalienável condição de pessoas investidas de dignidade e de direitos, como indivíduos destituídos de respeito e consideração, degradados ao nível de quem sequer tem direito a ter direitos, posto que se lhes nega, mediante discursos autoritários e excludentes, o reconhecimento da legitimidade de sua própria existência.

Para esse fim, determinados grupos políticos e sociais, inclusive confessionais, motivados por profundo preconceito, vêm estimulando o desprezo, promovendo o repúdio e disseminando o ódio contra a comunidade LGBT, recusando-se a admitir, até mesmo, as noções de gênero e de orientação sexual como aspectos inerentes à condição humana, buscando embaraçar, quando não impedir, o debate público em torno da transsexualidade e da homossexualidade, por meio da arbitrária desqualificação dos estudos e da inconcebível negação da consciência de gênero, reduzindo-os à condição subalterna de mera teoria social ( a denominada "ideologia de gênero") ${ }^{28}$

Primeiramente pode-se afirmar que apesar de conceituar o que se entende por comunidade "LGBT”, "LGBTQ”, “LGBTI+” e outros, não é realizada a conceituação específica dos termos que compõem estes grupos, salvo que estes são compostos de pessoas cuja orientação sexual ou identidade de gênero não são cisheteronormativas, isto é, não é heterossexual e cisgênero.

Em suma, é mencionado que na comunidade LGBT estão inclusos, dentre outros, gays, lésbicas, bissexuais, transexuais, travestis e transgêneros, além de denotado que estes grupos estão juntos no que é chamado de comunidade LGBT justamente por serem distintos, diferenciados pelas questões de sexualidade e gênero, e encontrarem-se em situação de vulnerabilidade, agravada por práticas discriminatórias e atentatórias aos seus direitos e garantias fundamentais ${ }^{29}$ como demonstrado pelo relator ministro Celso de Mello em seu voto na $\mathrm{ADO} 26$ / DF.

Por fim, a ação direta de inconstitucionalidade, institui a interpretação de que crimes de homotransfobia devem ser entendidos como equiparados aos crimes de racismo, e que os

\footnotetext{
${ }_{28}^{28}$ BRASIL. Supremo Tribunal Federal. Inteiro Teor da Ação Direta de Inconstitucionalidade por Omissão n. 26. Relator Celso de Mello. Diário de Justiça n. or/o7/2019, p. 48 e 49. Disponível em: http://portal.stf.jus.br/processos/detalhe.asp?incidente=4515053. Acesso em: 27 ago. 2021.

${ }^{29}$ BRASIL. Supremo Tribunal Federal. Inteiro Teor da Ação Direta de Inconstitucionalidade por Omissão n. 26. Relator Celso de Mello. Diário de Justiça n. or/o7/2org. Disponível em: http://portal.stf.jus.br/processos/detalhe.asp?incidente=4515053. Acesso em: 27 ago. 2021.
} 
atos tipificados de homotransfobia serão julgados nos termos dos tipos legislativos referentes as questões raciais, efetivamente suprindo a omissão legislativa. ${ }^{30}$

\subsection{Da Aplicação da Legislação no Caso Concreto}

Como demonstrado na Ação Direta de Inconstitucionalidade n 26, a comunidade LGBTQIA+ é caracterizada por ser composta de pessoas não-cisheteronormativas, esta definição constante na decisão do plenário do Supremo Tribunal Federal é suficiente para fundamentar a equiparação de atos homotransfóbicos aos atos racistas ${ }^{31}$, portanto, dada a credibilidade do plenário do STF, depreende-se que esta definição é suficiente para efetividade da decisão e, logicamente, para aplicação no caso concreto.

Se a definição das fontes do direito é suficiente, mas a homotransfobia ainda é presente face a comunidade LGBT, faz-se necessário a investigação de outros âmbitos para identificar onde a aplicação da lei esteja falhando.

Dito isso, é notória a homofobia e a transfobia presentes na sociedade brasileira ${ }^{32}{ }^{33}$, a ponto de afetar mesmo quem não compõe a comunidade LGBT. ${ }^{34}$

A LGBTfobia no Brasil foi institucionalizada pelos primeiros três séculos de colonização, ${ }^{35}$ esta institucionalização foi mantida no Brasil devido a fortíssima influência religiosa no governo brasileiro da época. Ademais, apesar de sua descriminalização, as práticas homossexuais e homoafetivas continuaram a ser condenadas pela sociedade e pelos dogmas religiosos da época até meados do Século XIX. ${ }^{36}$

Mesmo nos dias atuais a história da caça e da punição aos LGBTs denota seus efeitos, como explica PEIXOTO (2018):

\footnotetext{
${ }^{30}$ Ibid.

${ }^{31}$ Ibid.

${ }^{32}$ MELO, George Souza de. O caso de Dandara dos Santos: sobre a violência e o corpo dissidente. Revista Periódicus, [S. 1.], v. I, n. Io, p. 72-84, 2018. Disponível em: https://periodicos.ufba.br/index.php/revistaperiodicus/article/view/2775I. Acesso em: 12 set. 2021.

${ }^{33}$ PEIXOTO, Valdenízia Bento. Violência contra LGBTs no Brasil: premissas históricas da violação no Brasil. Revista Periódicus, $[S . \quad 1],$.$\quad v. \quad$ I, $\quad$ n. $\quad$ Io, $\quad$ p. $\quad 7-23, \quad$ 2018. $\quad$ Disponível $\quad \mathrm{em:}$ https://periodicos.ufba.br/index.php/revistaperiodicus/article/view/28014. Acesso em: I2 set. 202I.

34 SIMONATO, Maurício. Homem confessa agressão a pai e filho por confundi-los com casal gay e é libertado. UOL. São Paulo. I9 set. 20II. Últimas Notícias. Disponível em: https://noticias.uol.com.br/cotidiano/ultimasnoticias/2011/o7/19/apos-confessar-agressao-a-pai-e-filho-por-confundi-los-com-casal-gay-suspeito-e-libertado.htm. Acesso em: 13 set. 2021.

${ }^{35}$ PEIXOTO, Valdenízia Bento. Violência contra LGBTs no Brasil: premissas históricas da violação no Brasil. Revista Periódicus, [S. l.], $\quad$ v. $\quad$ I, $\quad$ n. $\quad$ Io, $\quad$ p. $7-23, \quad 2018, \quad$ p. $\quad 9 . \quad$ Disponível em: https://periodicos.ufba.br/index.php/revistaperiodicus/article/view/28014. Acesso em: 13 set. 202I.

${ }^{36}$ Ibid.
} 
O fato é que, mesmo transpassados cerca de 400 anos, ainda persistem máculas das abordagens criminalísticas e pecadoras sobre a homossexualidade do Brasil colonial e da Primeira República, à época considerado neófito em termos de desenvolvimento político, social e cultural. As razões da permanência deste tipo de abordagem neste século XXI podem se diferenciar daqueles do período seiscentista. O que se encontra em voga hoje é um amálgama de discursos engendrados por algumas frentes que representam o poder hegemônico de uma elite política, econômica e religiosa. Essa mesma elite que está no controle do Estado brasileiro se emaranhou nas instituições de poder, que não se restringem mais à tríade do executivo, legislativo e judiciário. Hoje soma-se, mesmo informalmente, a esses três poderes republicanos, o poder religioso e o midiático, formando, portanto, um pentágono estruturado e coeso de dominação. ${ }^{37}$

Considerando que o discurso permeia as várias esferas dos três poderes, seria presunçoso assumir que estes mesmos discursos não se fariam presentes nos vários âmbitos jurídico-sociais. A violência contra LGBTs é propagada pelas próprias instituições públicas e privadas, ${ }^{38}$ pelas ações de seus membros.

Essa violência afeta de maneira direta a garantia aos poucos direitos necessários à isonomia garantidos a comunidade LGBT. Direitos esses que são conquistados a muito esforço, como denota PEIXOTO (2018):

[...] o Estado, na tentativa de se manter assíduo e responsável com os/as cidadão/ãs, empreende políticas compensatórias de reconhecimento (nome social para transexuais, campanhas de combate ao preconceito, união civil), mas que não provocam transformações estruturais na vida e na sociabilidade plena de LGBTs, inclusive porque a disputa política para o avanço e a ampliação das políticas sociais é travada também contra políticos de alas conservadoras que não admitem a questão como um elemento de direitos humanos ${ }^{39}$

Apesar de as discriminações em razão de orientação sexual ou identidade de gênero terem sido criminalizadas, a população LGBT resiste a denunciar estas violações devido a sensação de impunidade relativa a seus agressores, o que sedimenta a ideia de que não terão a devida proteção mesmo em momento de grande vulnerabilidade, levando a um número muito baixo de denúncias colhidas em delegacias relativas aos casos reportados..$^{\circ}$

Esta sensação de impunidade é fortemente relacionada com o receio da vítima que pretende denunciar um crime de homotransfobia em uma delegacia, seja por medo de ser humilhada em decorrência de sua orientação sexual ou identidade de gênero, seja por medo

\footnotetext{
37 Ibid. p. 12.

${ }^{8}$ PEIXOTO, Valdenízia Bento. Violência contra LGBTs no Brasil: premissas históricas da violação no Brasil. Revista Periódicus, $[S . \quad$ l.], v. I, n. Io, p. 7-23, 2018, p. is e i6. Disponível em: https://periodicos.ufba.br/index.php/revistaperiodicus/article/view/28014. Acesso em: 13 set. 2021.

${ }^{39}$ Ibid. p. 16

${ }^{40} \mathrm{JESUS}$, Jaqueline Gomes de. Homofobia: identificar e prevenir. Rio de Janeiro: Metanoia, 2019.
} 
de ter sua orientação sexual exposta, ou mesmo por desacreditar que a polícia se empenhará na investigação de seu caso. ${ }^{41}$

Porém, mesmo com a homotransfobia enraizada em vários âmbitos jurídico-socais, uma parcela das unidades da federação, que inclui São Paulo, Paraíba, Piauí e Sergipe, conta com delegacias especializadas em crimes contra o público LGBT. ${ }^{42}$

Também foram elaborados sistemas de coleta de informações para criação de banco de dados sobre crimes de ódio homotransfóbicos, permitindo que planos de ação possam ser traçados com o objetivo de implementar políticas públicas de maneira correta e eficaz. ${ }^{43}$ Esses desenvolvimentos denotam um lento, mas certo progresso da justiça brasileira na luta contra a homotransfobia.

Por fim, é importante trazer à luz que a $\mathrm{ADO}$ 26/DF equipara expressões homotransfóbicas a expressões racistas, mas não equipara injúrias homotransfóbicas as injúrias raciais. ${ }^{44} \mathrm{O}$ racismo atinge uma coletividade indeterminada de indivíduos, enquanto a injúria racial é direcionada a alguém em específico, a $\mathrm{ADO}$ 26/DF claramente versa sobre racismo, mas não trata de injúria racial, essa lacuna na interpretação do tipo penal foi de grande indignação para a comunidade LGBTQIA+, já que não trouxe na íntegra os efeitos esperados pela sociedade em relação à criminalização da homofobia. ${ }^{45}$ Não tipificar a homofobia e a transfobia como causas para a injúria racial é um dos fatores que colaboram para a sensação de impunidade e insegurança que se faz tão presente face aqueles que denunciam tais condutas.

Apesar disso, não tratar da injúria racial não deslegitima a $\mathrm{ADO}$ 26/DF como o marco que definiu a criminalização da homotransfobia no Brasil.

\footnotetext{
${ }^{41}$ RAMOS, Silvia. Minorias e prevenção da violência. In: Karyna Sposato (org.). Das políticas de segurança pública às políticas públicas de segurança. São Paulo: Ilanud, 2002, p. 27-40. Disponível em: https://cesecseguranca.com.br/textodownload/minorias-e-prevencao-da-violencia/. Acesso em: 27 out. 2021 ${ }^{42}$ SAIBA como cada estado brasileiro trata crimes contra LGBTs. Exame, [S. 1.], 24 mar. 2or6. Disponível em: https://exame.com/brasil/saiba-como-cada-estado-brasileiro-trata-crimes-contra-lgbts/. Acesso em: 27 out. 2021.

${ }^{43}$ RAMOS, Silvia. Minorias e prevenção da violência. In: Karyna Sposato (org.). Das políticas de segurança pública às políticas públicas de segurança. São Paulo: Ilanud, 2002, p. 27-40. Disponível em: https://cesecseguranca.com.br/textodownload/minorias-e-prevencao-da-violencia/. Acesso em: 28 out. 2021 ${ }^{4}$ NEVES, Felipe Costa Rodrigues; DINIZ, Bianca; ARAUJO, Maria Paes Barreto de. A criminalização da homofobia: como a constituição federal aborda a (des)igualdade, as discriminações e o racismo?. Migalhas, [S. 1.], o8 mar. 2019. Disponível em: https://www.migalhas.com.br/coluna/constituicao-na-escola/297569/a-criminalizacao-da-homofobia-como-a-constituicao-federal-aborda-a--des-igualdade--as-discriminacoes-e-o-racismo. Acesso em: 29 out. 2021. ${ }^{45}$ DESIDERI, Leonardo. Entidade pede que STF classifique ofensa individual a LGBT como injúria racial. Gazeta do Povo, Brasília, o7 ago. 2020. Disponível em: https://www.gazetadopovo.com.br/vida-e-cidadania/entidade-pede-stf-homofobiainjuria-racial/. Acesso em: 29 out. 2021.
} 


\section{CONCLUSÃO}

Face o exposto, depreende-se de todo o conteúdo dos votos dos relatores na $\mathrm{ADO}_{26} 6$ que não é realizada a conceituação dos grupos que compõem a comunidade LGBT por não haver a necessidade de se fazê-lo. A terminologia constante no texto legislativo e na decisão do plenário do STF são suficientes para referenciar adequadamente as comunidades que compõem a comunidade LGBTQIA+ e não interferem diretamente na efetividade da legislação.

A comunidade LGBTQIA+ como um todo é definida como um grupo que sofre com constantes práticas atentatórias aos seus direitos e liberdades, em decorrência de sua identidade de gênero ou de sua orientação sexual, que não é cisheteronormativa.

A ausência de definição dos termos que compõem a comunidade LGBT não faz diferença no caso prático, já que a comunidade LGBTQ encontra-se unida devido a sua vulnerabilidade decorrente de orientação sexual e/ou identidade de gênero face a cisheteronormatividade enraizada na sociedade devido ao contexto histórico brasileiro, o que torna não só impraticável a conceituação de cada um de seus grupos no texto legislativo como também ineficiente e desnecessária à eficaz aplicação da lei, dada a mutabilidade do grupo e a quantidade virtualmente infinita de subcomunidades abarcadas.

Porém, é inegável a falta de preparo de boa parte dos servidores públicos para lidar com casos de homotransfobia, o que decerto mina a efetividade da decisão do STF, impedindo que a equiparação da homotransfobia ao racismo seja plenamente eficaz.

Não obstante, houve um pequeno, mas significativo progresso no combate a homotransfobia, por meio da coleta de informações a respeito dos crimes de ódio em razão de expressão de gênero e de orientação sexual, e da criação de canais de denúncia para práticas homotransfóbicas.

Portanto é possível concluir que a problemática da eficácia da legislação na proteção da comunidade LGBT decorre de uma questão paradigmática dentro de um contexto sociocultural, do funcionamento interno das instituições estatais e do preparo dos servidores públicos, e não puramente do âmbito positivo, isto é, a falha na efetiva proteção da comunidade LGBTQIA + não decorre unicamente da omissão legislativa. A homotransfobia que permeia os próprios operadores do direito afeta de maneira direta a efetividade da legislação brasileira na proteção da comunidade LGBTQIA+ apesar de terem sido feitos 
avanços consideráveis no combate a homotransfobia, considerando que a legislação não carece de recursos que permitam a interpretação da legislação ou novação de texto legislativo para proteger a comunidade e tampouco o Estado carece de recursos que permitam a efetiva implementação destas normas.

\section{REFERÊNCIAS}

Answers to your questions for a better understanding of sexual orientation and homosexuality. American Psychological Association. 2008. Disponível em: https://www.apa.org/topics/lgbtq/orientation. Acesso em: I3 abr. 202I

BERRILL, N. J.. Sex. Encyclopædia Britannica Online. 2013. Disponível em: https://www.britannica.com/science/sex. Acesso em: I3 abr. 202I

BORTOLETTO, Guilherme Engelman. LGBTQIA+: identidade e alteridade na comunidade. Trabalho de conclusão de curso apresentado como requisito parcial para obtenção do título de Especialista em Gestão de Produção Cultural. São Paulo/SP, 2019.

BRASIL. [Constituição (1988)]. Constituição da República Federativa do Brasil de 1988. Brasília, DF: Presidência da República, [2016]. Disponível em: http://www.planalto.gov.br/ccivil_03/constituicao/constituicao.htm. Acesso em: 13 abr. 2021

BRASIL. Supremo Tribunal Federal. Ação direta de inconstitucionalidade por omissão no 26/DF - Distrito Federal. Relator: Ministro Celso de Mello. 2019. Disponível em: http://www.stf.jus.br/arquivo/cms/noticiaNoticiaStf/anexo/ADO26votoMAM.pdf.

Acesso em: 13 abr. 2021.

BRASIL. Supremo Tribunal Federal. Inteiro Teor da Ação Direta de Inconstitucionalidade por Omissão n. 26. Relator Celso de Mello. Diário de Justiça n. or/o7/2019 Disponível em: http://portal.stf.jus.br/processos/detalhe.asp?incidente $=4515053$. Acesso em: 26 ago. 2021.

BRASIL. Lei no I0.216 de 6 de abril de 200I. Dispõe sobre a proteção e os direitos das pessoas portadoras de transtornos mentais e redireciona o modelo assistencial em saúde mental. Diário Oficial da União: seção I, Brasília, DF, p. 2, o9 abr. 200I. Disponível em: http://www.planalto.gov.br/ccivil_03/leis/leis_200I/lio2I6.htm. Acesso em: o9 set 202I.

BRASIL. Lei no 11.340 de 07 de agosto de 2006. Cria mecanismos para coibir a violência doméstica e familiar contra a mulher [...] e dá outras providências. Diário Oficial da União: seção I, Brasília, DF, p. I, o8 ago. 2008. Disponível em: http://www.planalto.gov.br/ccivil_03/_ato2004-2006/2006/lei/lir340.htm. Acesso em: o9 set. 202I. 
BRITANNICA, The Editors of Encyclopædia. Gender identity. Encyclopædia Britannica Online. 2020. Disponível em: https://www.britannica.com/topic/gender-identity. Acesso em: I3 Abr. 2021.

DESIDERI, Leonardo. Entidade pede que STF classifique ofensa individual a LGBT como injúria racial. Gazeta do Povo, Brasília, 07 ago. 2020. Disponível em: https://www.gazetadopovo.com.br/vida-e-cidadania/entidade-pede-stf-homofobiainjuria-racial/. Acesso em: 29 out. 202I.

FILHO, Kleber Prado e LEMOS, Flavia Cristina Silveira. Uma breve cartografia da luta antimanicomial no Brasil. Contemporânea - Revista de Sociologia da UFSCar. São Carlos, v. 2, n. I, jan-jun 2012, pp. 45-63. Disponível em: https://www.contemporanea.ufscar.br/index.php/contemporanea/article/view/59/32.

Acesso em: o9 set 202I

JESUS, Jaqueline Gomes de. Homofobia: identificar e prevenir. Rio de Janeiro: Metanoia, 2019.

LAVIERI, Fernando. As trans exigem a lei Maria da Penha. ISTOÉ. Rio de Janeiro, n. 2696. I7 set. 202I. Comportamento. Disponível em: https://istoe.com.br/as-trans-exigem-a-leimaria-da-penha/. Acesso em: 25 set 2021.

MANDALA da Diversidade Sexual. Ary Ney Chaicoski Junior, Fabio Dezo, Thiago 1290 Campos. 2019. CC BY-SA 4.o. https://creativecommons.org/licenses/by-sa/4.o, via Wikimedia Commons. Disponível em: https://commons.wikimedia.org/wiki/File:Mandala_da_Diversidade_Sexual.svg. Acesso em: I3 abr. 2021.

MELO, George Souza de. O caso de Dandara dos Santos: sobre a violência e o corpo dissidente. Revista Periódicus, [S. 1.], v. I, n. Io, p. 72-84, 2018. Disponível em: https://periodicos.ufba.br/index.php/revistaperiodicus/article/view/27751. Acesso em: I2 set. 202I.

NEVES, Felipe Costa Rodrigues; DINIZ, Bianca; ARAUJO, Maria Paes Barreto de. A criminalização da homofobia: como a constituição federal aborda a (des)igualdade, as discriminações e o racismo?. Migalhas, [S. 1.], o8 mar. 2019. Disponível em: https://www.migalhas.com.br/coluna/constituicao-na-escola/297569/a-criminalizacaoda-homofobia--como-a-constituicao-federal-aborda-a--des-igualdade--as-discriminacoes-eo-racismo. Acesso em: 29 out. 2021.

PEIXOTO, Valdenízia Bento. Violência contra LGBTs no Brasil: premissas históricas da violação no Brasil. Revista Periódicus, [S. 1.], v. I, n. Io, p. 7-23, 2018. Disponível em: https://periodicos.ufba.br/index.php/revistaperiodicus/article/view/28014. Acesso em: 12 set. 2021.

RAMOS, Silvia. Minorias e prevenção da violência. In: Karyna Sposato (org.). Das políticas de segurança pública às políticas públicas de segurança. São Paulo: Ilanud, 2002, p. 27-40. 
Disponível em: https://cesecseguranca.com.br/textodownload/minorias-e-prevencao-daviolencia/. Acesso em: 28 out. 2021

RIO DE JANEIRO. Tribunal de Justiça do estado do Rio de Janeiro, Comarca de São Gonçalo. Decisão. Processo no oor879o-25.2017.8.19.0oo4. Juízo de Direito da Vara de Violência Doméstica e Familiar Contra a Mulher. Disponível em: https://www.conjur.com.br/dl/lei-maria-penha-tambem-protege-mulher.pdf. Acesso em: o9 set 2021.

STJ julgará medidas protetivas em favor de mulher trans. Migalhas, [S. 1.], 30 maio 202I. Disponível em: https://www.migalhas.com.br/quentes/346238/stj-julgara-medidasprotetivas-em-favor-de-mulher-trans. Acesso em: 27 out. 2021.

SAIBA como cada estado brasileiro trata crimes contra LGBTs. Exame, [S. 1.], 24 mar. 2016. Disponível em: https://exame.com/brasil/saiba-como-cada-estado-brasileiro-trata-crimescontra-lgbts/. Acesso em: 27 out. 2021.

SIMONATO, Maurício. Homem confessa agressão a pai e filho por confundi-los com casal gay e é libertado. UOL. São Paulo. I9 set. 20Ir. Últimas Notícias. Disponível em: https://noticias.uol.com.br/cotidiano/ultimas-noticias/201I/o7/r9/apos-confessaragressao-a-pai-e-filho-por-confundi-los-com-casal-gay-suspeito-e-libertado.htm. Acesso em: 13 set. 2021.

WHAT is intersex?. Intersex Human Rights Australia. 2013. Disponível em: https://ihra.org.au/r8i06/what-is-intersex/. Acesso em: 13 abr. 2021 